\title{
Comparison of equations for estimating glomerular filtration rate in screening for chronic kidney disease in asymptomatic black Africans: a cross sectional study
}

Geoffrey Omuse ${ }^{1 *}$, Daniel Maina', Jane Mwangi², Caroline Wambua², Alice Kanyua ${ }^{3}$, Elizabeth Kagotho', Angela Amayo ${ }^{4}$, Peter Ojwang ${ }^{5}$ and Rajiv Erasmus ${ }^{6}$

\begin{abstract}
Background: Several equations have been developed to estimate glomerular filtration rate (eGFR). The common equations used were derived from populations predominantly comprised of Caucasians with chronic kidney disease (CKD). Some of the equations provide a correction factor for African-Americans due to their relatively increased muscle mass and this has been extrapolated to black Africans. Studies carried out in Africa in patients with CKD suggest that using this correction factor for the black African race may not be appropriate. However, these studies were not carried out in healthy individuals and as such the extrapolation of the findings to an asymptomatic black African population is questionable. We sought to compare the proportion of asymptomatic black Africans reported as having reduced eGFR using various eGFR equations. We further compared the association between known risk factors for CKD with eGFR determined using the different equations.
\end{abstract}

Methods: We used participant and laboratory data collected as part of a global reference interval study conducted by the Committee of Reference Intervals and Decision Limits (C-RIDL) under the International Federation of Clinical Chemistry (IFCC). Serum creatinine values were used to calculate eGFR using the Cockcroft-Gault (CG), re-expressed 4 variable modified diet in renal disease (4V-MDRD), full age spectrum (FAS) and chronic kidney disease epidemiology collaboration equations (CKD-EPI). CKD classification based on eGFR was determined for every participant.

Results: A total of 533 participants were included comprising 273 (51.2\%) females. The 4V-MDRD equation without correction for race classified the least number of participants (61.7\%) as having an eGFR equivalent to CKD stage G1 compared to $93.6 \%$ for CKD-EPI with correction for race. Only age had a statistically significant linear association with eGFR across all equations after performing multiple regression analysis. The multiple correlation coefficients for CKD risk factors were higher for CKD-EPI determined eGFRs.

Conclusions: This study found that eGFR determined using CKD-EPI equations better correlated with a prediction model that included risk factors for CKD and classified fewer asymptomatic black Africans as having a reduced eGFR compared to 4V-MDRD, FAS and CG corrected for body surface area.

Keywords: MDRD, CKD-EPI, Cockcroft-Gault, FAS, eGFR

\footnotetext{
* Correspondence: 9_omuse@yahoo.com

'Department of Pathology, Aga Khan University Hospital Nairobi, P.O. Box

30270-00100, Nairobi, Kenya

Full list of author information is available at the end of the article
} 


\section{Background}

Routine reporting of estimated glomerular filtration rate (eGFR) by medical laboratories for every serum creatinine request has been encouraged as a way of screening for chronic kidney disease (CKD) and has been shown to increase the absolute number of appropriate referrals to nephrologists [1]. Patients with early CKD may be asymptomatic and therefore reporting eGFR may help in early detection and appropriate interventions to stop or reverse progression of the disease [2].

The use of eGFR equations instead of creatinine clearance $(\mathrm{CrCl})$ is preferred due to the difficulties associated with accurately collecting a $24 \mathrm{~h}$ urine sample. The most popular equations for estimating GFR are Cockcroft-Gault (CG), 4 variable modified diet in renal disease ( $4 \mathrm{v}-\mathrm{MDRD}$ ) and chronic kidney disease epidemiology collaboration (CKD-EPI). The CG equation was derived from an inpatient population comprising predominantly male patients with CKD [3]. The equation doesn't correct for race and one requires the patient's height and weight to correct for body surface area (BSA) in order to accurately classify CKD. The $4 \mathrm{v}-\mathrm{MDRD}$ equation was derived from a population with kidney disease comprising a predominantly white population. Despite the low percentage of African-Americans in this study, they determined a correction for race [4]. It has been assumed, given the ancestral linkage between African Americans and black Africans that this correction should apply to black Africans. However, a study carried out in South Africa that measured GFR in black South Africans with established CKD or risk factors for developing CKD concluded that eGFR based on the $4 \mathrm{v}-\mathrm{MDRD}$ equation without correction for race better correlated with measured GFR (mGFR) and had less bias [5]. A similar study carried out in Ghana in a rural African population arrived at a similar conclusion, however, this study compared eGFR to creatinine clearance [6]. Both CG and 4v-MDRD have been shown to underestimate normal and high mGFR values with a greater negative bias seen with CG $[7,8]$. One of the drawbacks of the $4 \mathrm{v}-\mathrm{MDRD}$ equation is that it doesn't accurately classify patients with early CKD, in particular those with values $>60 \mathrm{ml} / \mathrm{min} / 1.73 \mathrm{~m}^{2}$. This is not surprising given that it was derived from patients with CKD who had a mean eGFR of $39.8 \mathrm{ml} / \mathrm{min} / 1.73 \mathrm{~m}^{2}$. The utility of this equation in screening for CKD in an asymptomatic patient with no known risk factors for CKD is questionable given that subjectively healthy individuals generally have an eGFR in the range where the $4 \mathrm{v}-\mathrm{MDRD}$ equation is inaccurate. The CKD-EPI equation has been found to better correlate with mGFR especially in those with eGFR $>60 \mathrm{ml} / \mathrm{min} / 1.73 \mathrm{~m}^{2}$ [9]. In a study carried out in Kenya amongst HIV patients with a median mGFR of $115 \mathrm{ml} / \mathrm{min} / 1.73 \mathrm{~m}^{2}$, both CKD-EPI and 4v-MDRD performed better without correction for race with CKD-EPI estimates being more precise [10]. A new equation called the full age spectrum (FAS) equation has been developed by Pottel et al. which factors in correction for race, age and gender by including population specific mean or median serum creatinine values in the determination of eGFR. This equation has the advantage of being applicable across different age groups from children as young as 2 years to the elderly above 65 years of age. The equation is yet to be validated in a black African population and was derived from population datasets largely comprising Caucasians [11]. Most of the studies done in Africa that have concluded that correcting for race is not necessary for a black African population were carried out in populations comprising patients with CKD or at a high risk of developing CKD. The extrapolation of this finding to an asymptomatic population should not be done without evidence that this observation is consistent.

None of the eGFR equations that are routinely used were derived from a black African population and as such their appropriateness in assessing kidney function in this population needs to be evaluated. Since creatinine generation is determined primarily by muscle mass and dietary intake [12], it is reasonable to assume that the performance of eGFR equations will be influenced by the extent to which the body habitus of an African population differs from the reference populations used when deriving them. Given the paucity of data on the performance of these equations in a subjectively healthy population, we compared eGFR determined using various eGFR equations and assessed which eGFR values best correlated with known risk factors for CKD and the proportion of asymptomatic black Africans with no known risk factors for CKD classified as having a reduced or normal eGFR by each equation.

\section{Methods}

We determined eGFR using single measurements of serum creatinine from Kenyans participating in a crosssectional multicenter, multinational, global reference interval study which is part of an initiative by the Committee of Reference Intervals and Decision Limits (C-RIDL) under the auspices of the International Federation of Clinical Chemistry (IFCC). The aim of the study is to determine reference intervals for common laboratory tests across different geographical regions and populations, and to explore determinants of variation in reference intervals. Kenya is one of the three participating countries in Africa, the other ones being Nigeria and South Africa. For the Kenyan study, we recruited subjectively healthy black African adults who met the inclusion criteria as spelt out in the published protocol [13]. Participants were recruited from Nairobi which is the capital city, Kiambu county which is in central Kenya, Kisii which is in the western part of Kenya, and Nakuru county which is in the Great 
Rift valley. Recruitment was carried out between January and October 2015. All participants had undergone an overnight fast and written informed consent was sought from each participant after giving a written and verbal explanation of the study. Recruitment was stratified into 4 age groups: $18-29,30-39,40-49$ and $50-65$ years with almost similar numbers of males and females in each age strata. The recruitment procedure, sample handling and analysis has previously been described [14]. Briefly, all participants had measurements of blood pressure (BP), abdominal circumference and body mass index (BMI) done, samples were collected and centrifuged within $4 \mathrm{~h}$ after collection and stored at $-80^{\circ} \mathrm{C}$ until shipment on dry ice to the Pathcare reference laboratory in South Africa. As part of the reference interval study, all participating laboratories used a common mini-panel of sera with assigned values to ensure accuracy of reported results and alignment of values if any biases were identified. Urine samples to test for haematuria and proteinuria were not collected. Serum creatinine was determined using a standardized kinetic colour test (Jaffé method) and fasting plasma glucose (FPG) by an enzymatic UV test (hexokinase method) both measured on a Beckman AU5800 (Schizuoka, Japan).

Calculation of body surface area (BSA) was done using the DuBois method [15]: BSA $\left(\mathrm{m}^{2}\right)=\left[71.84 \times\right.$ weight $(\mathrm{kg})^{0.425} \times$ height $\left.(\mathrm{cm})^{0.725}\right] / 10000$..

Calculation of eGFR $\left(\mathrm{mL} / \mathrm{min} / 1.73 \mathrm{~m}^{2}\right)$ was done using the following equations:

Re-expressed 4-v MDRD [16]

$$
\begin{aligned}
175 & \times[\mathrm{S}-\mathrm{Cr}(\mu \mathrm{mol} / \mathrm{L}) / 88.4]^{-1.154} \times \text { age }(\text { years })^{-0.203} \\
& \times(0.742 \text { if female }) \times(1.212 \text { if African American })
\end{aligned}
$$

Cockcroft-Gault normalized to $1.73 \mathrm{~m}^{2}$ [3]

$[(140 \times$ age in years $) \times$ weight $(\mathrm{kg}) \times(0.85$ if female $) \times 1.73(\mathrm{~m} 2)] /$

$\left[\mathrm{S}-\mathrm{Cr}(\mu \mathrm{mol} / \mathrm{L}) \times 0.814 \times \mathrm{BSA}\left(\mathrm{m}^{2}\right)\right]$

CKD-EPI for blacks [9]

Female with Creatinine $\leq 62 \mu \mathrm{mol} / \mathrm{L} ; 166$

$$
\times\left(\mathrm{S}_{\mathrm{cr}} / 61.9\right)^{-0.329} \times(0.993)^{\text {Age }}
$$

Female with Creatinine $>62 \mu \mathrm{mol} / \mathrm{L} ; 166$

$$
\times\left(\mathrm{S}_{\mathrm{cr}} / 61.9\right)^{-1.209} \times(0.993)^{\text {Age }}
$$

Male with Creatinine $\leq 80 \mu \mathrm{mol} / \mathrm{L} ; 163$

$$
\times\left(\mathrm{S}_{\mathrm{cr}} / 79.6\right)^{-0.411} \times(0.993)^{\text {Age }}
$$

Male with Creatinine $>80 \mu \mathrm{mol} / \mathrm{L} ; 163$

$$
\times\left(\mathrm{S}_{\mathrm{cr}} / 79.6\right)^{-1.209} \times(0.993)^{\mathrm{Age}}
$$

CKD-EPI for other races [9]
Female with Creatinine $\leq 62 \mu \mathrm{mol} / \mathrm{L} ; 144$

$$
\times\left(\mathrm{S}_{\mathrm{cr}} / 61.9\right)^{-0.329} \times(0.993)^{\text {Age }}
$$

Female with Creatinine $>62 \mu \mathrm{mol} / \mathrm{L} ; 144$

$$
\times\left(\mathrm{S}_{\mathrm{cr}} / 61.9\right)^{-1.209} \times(0.993)^{\text {Age }}
$$

Male with Creatinine $\leq 80 \mu \mathrm{mol} / \mathrm{L} ; 141$

$$
\times\left(\mathrm{S}_{\mathrm{cr}} / 79.6\right)^{-0.411} \times(0.993)^{\text {Age }}
$$

Male with Creatinine $>80 \mu \mathrm{mol} / \mathrm{L} ; 141$

$$
\times\left(\mathrm{S}_{\mathrm{cr}} / 79.6\right)^{-1.209} \times(0.993)^{\text {Age }}
$$

FAS equation [11].

$2-40$ years; $107.3 /(\mathrm{Scr} / \mathrm{Q})$.

$>40$ years; $(107.3 /[\mathrm{Scr} / \mathrm{Q}]) 0.988^{\mathrm{Age}-40}$.

Where Scr is serum creatinine, $Q$ is the mean or median population specific serum creatinine, Age is in years.

Classification of CKD based on eGFR was done using the 2012 Kidney Disease: Improving Global Outcomes (KDIGO) clinical practice guidelines as follows [17]:

\begin{tabular}{lll}
\hline GFR category & GFR $\left(\mathrm{ml} / \mathrm{min} / 1.73 \mathrm{~m}^{2}\right)$ & Terms \\
\hline G1 & $\geq 90$ & Normal or high \\
G2 & $60-89$ & Mildly decreased \\
G3a & $45-59$ & Mildly to moderately decreased \\
G3b & $30-44$ & Moderately to severely decreased \\
G4 & $15-29$ & Severely decreased \\
G5 & $<15$ & Kidney failure \\
\hline
\end{tabular}

A cut off-of $75 \mathrm{ml} / \mathrm{min} / 1.73 \mathrm{~m}^{2}$ was also used to define reduced eGFR for participants less than 40 years of age as proposed by Pottel et al. [18]. Sample size calculation for the primary study was based on recommendations from the Clinical Laboratory Standards Institute (CLSI) which requires a minimum of 120 study participants per stratification in order to get $90 \%$ confidence limits around the upper and lower limits of a reference interval [19]. Since we had 4 age stratifications, a minimum sample size of 480 was required to achieve the primary objective for the reference interval study.

\section{Statistical analysis}

Descriptive and inferential statistics were performed using SPSS version 20 (IBM corp, Armonk, New York, USA). Medians and interquartile ranges (IQR) were calculated for continuous variables before and after stratification based on gender. Comparison of medians or mean ranks between males and females was done using the Mann-Whitney U test. Classification of eGFR was reported as proportions. Multiple regression analysis (MRA) was also performed to determine the extent to 
which the CKD risk factors independently added to the eGFR regression model. Calculation of eGFR, BSA and classification of CKD was done using Microsoft excel 2010 (Redmond, USA). A $p$-value less than 0.05 was considered statistically significant.

\section{Results}

A total of 533 participants were included comprising 260 (48.8\%) males and 273 (51.2\%) females. The median age, BMI and FPG between males and females wasn't statistically different neither was eGFR except when determined using CG corrected for BSA. Males had higher serum creatinine values. Five participants didn't have FPG assayed due to insufficient samples. A summary of the participants' demographic and clinical descriptive statistics are shown in Table 1.

Overall, women had higher eGFR compared to men. Of the 6 equations, the $4 \mathrm{v}-\mathrm{MDRD}$ equation without correction for race had the lowest median eGFR and classified the least number of participants (61.7\%) as having an eGFR $\geq 90 \mathrm{~mL} / \mathrm{min} / 1.73 \mathrm{~m}^{2}$ compared to $93.6 \%$ by CKD-EPI with correction for race as shown in Table 2 . The $4 \mathrm{v}-\mathrm{MDRD}$ equation without correction for race classified the highest percentage of participants $(0.9 \%)$ as having an eGFR $<60 \mathrm{ml} / \mathrm{min} / 1.73 \mathrm{~m}^{2}$. The number of individuals with an eGFR $<60 \mathrm{ml} / \mathrm{min} / 1.73 \mathrm{~m}^{2}$ was less than $1 \%$ regardless of the equation used. Using a cut off of $75 \mathrm{ml} / \mathrm{min} / 1.73 \mathrm{~m}^{2}$, the $4 \mathrm{v}-\mathrm{MDRD}$ equation without correction for race also classified the highest proportion of participants under the age of 40 years $(7.8 \%)$ as having reduced eGFR as shown in Table 2.

After multiple regression analysis, only age had an unstandardized coefficient (B) that was statistically significantly different from zero across all the 6 equations. Overall, the correlation between eGFR and risk factors for CKD varied depending on which equation was used. The 6 CKD risk factors evaluated had a stronger association with the CKD-EPI determined eGFRs as evidenced by higher multiple correlation coefficients as shown in Table 2.

\section{Discussion}

The prevalence of eGFR $<60 \mathrm{ml} / \mathrm{mim} / 1.73 \mathrm{~m}^{2}$ was less than $1 \%$ according to the 6 equations evaluated in this study which is reflective of the deliberate recruitment of healthy individuals for the reference interval study. In a randomly selected rural and urban adult population in Cameroon, Kaze et al. found that $10.9 \%$ had a CKD-EPI determined eGFR $<60 \mathrm{ml} / \mathrm{min} / 1.73 \mathrm{~m}^{2}$ with this being more common in the urban population [20]. Both the CKD-EPI and $4 \mathrm{v}-$ MDRD equations with correction for race did not classify any participant as having a reduced eGFR in our study largely comprised of an urban population. Assuming that a healthy population should predominantly have an eGFR $>90 \mathrm{ml} / \mathrm{min} / 1.73 \mathrm{~m}^{2}$, the CKD-EPI equation with correction for race classified more participants into stage G1 suggesting that it could be a more ideal equation when estimating eGFR in an

Table 1 Descriptive characteristics of participants

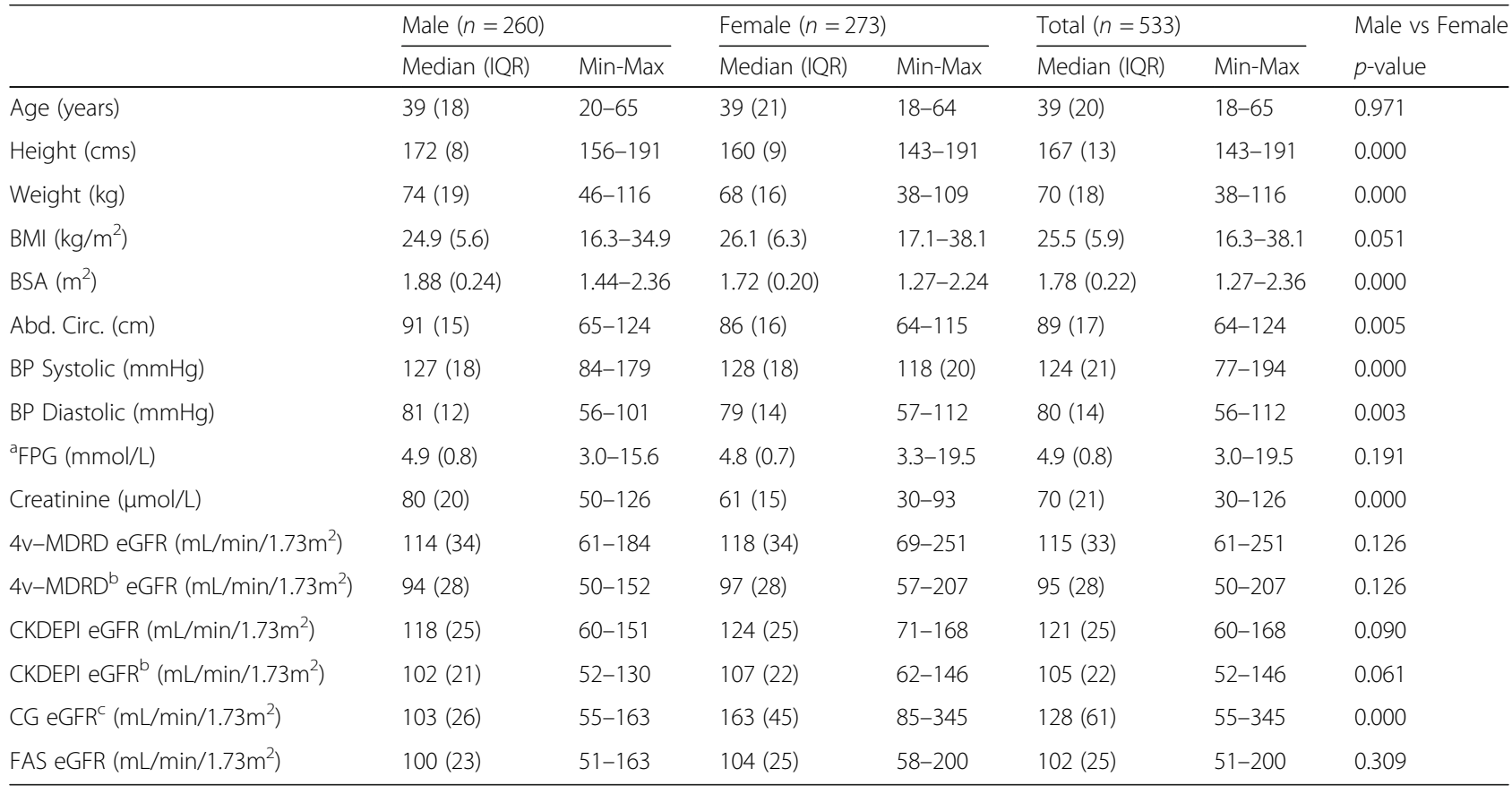

KEY: IQR Interquartile range, Abd.Circ. Abdominal circumference, BMI Body Mass Index, BP Blood pressure, FPG Fasting plasma glucose ( ${ }^{\mathrm{a}} 5$ males didn't have this test done), ${ }^{\mathrm{b}}$ Not corrected for race, ${ }^{\mathrm{c}}$ Corrected for body surface area 
Table 2 CKD classification and correlation of eGFR with risk factors

\begin{tabular}{|c|c|c|c|c|c|c|}
\hline & $\mathrm{CG}^{\mathrm{b}}$ & $4 \mathrm{~V}-\mathrm{MDRD}$ & $4 \mathrm{~V}-\mathrm{MDRD}^{\mathrm{a}}$ & CKD-EPI & $C K D-\left.E P\right|^{a}$ & FAS \\
\hline \multicolumn{7}{|l|}{$\begin{array}{l}\text { CKD classification based on eGFR } \\
\text { No. (\%) }\end{array}$} \\
\hline G1 & $478(89.7 \%)$ & $473(88.7 \%)$ & $329(61.7 \%)$ & $499(93.6 \%)$ & $433(81.2 \%)$ & $402(75.4 \%)$ \\
\hline G2 & $54(10.1 \%)$ & $60(11.3 \%)$ & $199(37.3 \%)$ & $34(6.4 \%)$ & 99 (18.6\%) & $129(24.2 \%)$ \\
\hline G3a & $1(0.2 \%)$ & $0(0.0 \%)$ & $5(0.9 \%)$ & $0(0.0 \%)$ & $1(0.2 \%)$ & $2(0.4 \%)$ \\
\hline $\begin{array}{l}\text { No. (\%) below } 40 \text { years with eGFR } \\
<75 \mathrm{ml} / \mathrm{min} / 1.73 \mathrm{~m}^{2}(n=270)\end{array}$ & $0(0.0 \%)$ & $0(0.0 \%)$ & $21(7.8 \%)$ & $0(0.0 \%)$ & $1(0.4 \%)$ & $5(1.9 \%)$ \\
\hline \multicolumn{7}{|l|}{ eGFR $\left(\mathrm{ml} / \mathrm{min} / 1.73 \mathrm{~m}^{2}\right)$ mean (SD) } \\
\hline $18-29$ years $(n=135)$ & $149.0(40.9)$ & $129.5(21.8)$ & $106.8(18.0)$ & $135.3(15.6)$ & $117.2(13.5)$ & $108.9(15.5)$ \\
\hline $30-39$ years $(n=135)$ & $136.7(39.2)$ & $112.1(20.2)$ & $92.6(16.7)$ & $119.1(15.8)$ & $103.2(13.7)$ & $102.9(15.8)$ \\
\hline $40-49$ years $(n=132)$ & $139.8(43.6)$ & $117.0(25.4)$ & $96.6(20.9)$ & $117.6(14.8)$ & $101.8(12.8)$ & $106.7(19.8)$ \\
\hline $50-65$ years $(n=131)$ & $120.8(35.1)$ & $111.9(25.0)$ & $92.3(20.6)$ & $107.6(15.2)$ & $93.2(13.1)$ & $92.2(18.4)$ \\
\hline Multiple correlation coefficient (R) & 0.563 & 0.305 & 0.306 & 0.568 & 0.568 & 0.350 \\
\hline \multicolumn{7}{|c|}{ Unstandardized (B) coefficients (standard error) } \\
\hline Age & $-0.621^{*}(0.151)$ & $-0.322^{*}(0.102)$ & $-0.267^{*}(0.084)$ & $-0.673^{*}(0.067)$ & $-0.579 *(0.058)$ & $-0.403^{*}(0.077)$ \\
\hline BMl & $7.418^{*}(0.567)$ & $-0.596(0.382)$ & $-0.491(0.315)$ & $-0.188(0.252)$ & $-0.129(0.218)$ & $-0.405(0.289)$ \\
\hline Systolic BP & $-0.485^{*}(0.140)$ & $-0.121(0.094)$ & $-0.099(0.078)$ & $-0.116(0.062)$ & $-0.102(0.054)$ & $-0.119(0.071)$ \\
\hline Diastolic BP & $0.237(0.202)$ & $0.139(0.136)$ & $0.115(0.112)$ & $0.142(0.090)$ & $0.124(0.078)$ & $0.117(0.103)$ \\
\hline Abd.Circ. & $-2.049 *(0.231)$ & $-0.178(0.156)$ & $-0.148(0.128)$ & $-0.184(0.103)$ & $-0.172(0.089)$ & $-0.028(0.118)$ \\
\hline FPG & $0.579(1.170)$ & $1.106(0.788)$ & $0.912(0.650)$ & $0.610(0.519)$ & $0.500(0.450)$ & $0.807(0.596)$ \\
\hline
\end{tabular}

KEY: Abd.Circ. Abdominal circumference, BP Blood pressure, BMI Body Mass Index, CKD Chronic kidney disease, FPG Fasting plasma glucose, ${ }^{a}$ Not corrected for

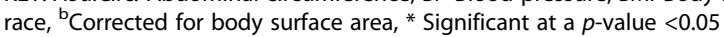

asymptomatic population not known to have risk factors for CKD. Unlike the MDRD equation which was derived from individuals with CKD, CKD-EPI was derived from a heterogeneous population that included healthy individuals [9]. Rule et al. used different equations to screen for CKD in a general population and found that equations derived from a CKD population gave higher estimates of CKD prevalence compared to equations derived from a population that included healthy individuals [21]. It is therefore not surprising that the CKD-EPI equation classified less participants as having a reduced eGFR compared to the $4 \mathrm{v}-\mathrm{MDRD}$ equation.

There has been a debate as to the suitability of the $60 \mathrm{ml} / \mathrm{min} / 1.73 \mathrm{~m}^{2}$ eGFR cut off for defining CKD in young adults and the elderly. Pottel et al. suggested that a cut off of $75 \mathrm{ml} / \mathrm{min} / 1.73 \mathrm{~m}^{2}$ would be more ideal in young adults under 40 years of age given that one would require a serum creatinine almost 1.8 times above the mean value for this population to achieve an eGFR less than $60 \mathrm{ml} /$ $\mathrm{min} / 1.73 \mathrm{~m}^{2}$ making this cut off quite insensitive to early increments in serum creatinine [18]. Gharbi et al. demonstrated that in an Arabic-Berber adult population in Morocco, using a cut off of $60 \mathrm{ml} / \mathrm{min} / 1.73 \mathrm{~m}^{2}$ resulted in under diagnosis of CKD in younger adults and over diagnosis in the elderly population [22]. In our study, based on a cut off of $75 \mathrm{ml} / \mathrm{min} / 1.73 \mathrm{~m}^{2}$, no one under the age of 40 years had reduced eGFR when determined using CG corrected for BSA, 4v-MDRD or CKD-EPI equations corrected for race. The FAS equation that can be applied across a wide age spectrum classified $5(1.9 \%)$ individuals less than 40 years of age as having a reduced eGFR compared to 21 (7.8\%) for the $4 \mathrm{v}-\mathrm{MDRD}$ equation without correction for race. In the absence of mGFR, testing for albuminuria or demonstrating persistence of reduced eGFR for at least 3 months, it is difficult to conclude which individuals truly had CKD and which equation was correctly classifying them as such.

We determined eGFR correlation with known risk factors for CKD such as age, BMI, BP, glycaemia and abdominal circumference. We assumed that in the absence of mGFR, the multiple correlation coefficient would serve as indirect proof of appropriateness for routine reporting of eGFR in an asymptomatic population as it is a measure of linear association between the predicted eGFR after factoring in the CKD risk factors and eGFR determined using the various equations. The CKD-EPI and CG corrected for BSA equations had the highest multiple correlation coefficients suggesting that the the model best fitted these equations. However, given that age is one of the components of the CG equation and both height and weight are used in the calculation of BMI and BSA, there is a possibility that the CG multiple correlation coefficient after correction for BSA is inaccurate due to possible collinearity. Age remained the only risk factor that showed a 
statistically significant linear association with eGFR across all eGFR equations. Matsha et al. demonstrated that age, gender and known history of hypertension were determinants of CKD stage 3-5 in a mixed ancestry population in South Africa. Surprisingly, this was not the case for FPG, BMI, systolic and diastolic BP. However, this study did not correlate eGFR with these potential risk factors but rather used logistic regression to determine the odds of having a reduced eGFR [23]. Kaze et al. concluded that in a rural and urban population in Cameroon, elevated systolic BP, presence of hypertension and diabetes were the main predictors of albuminuria and CKD [20]. In the Democratic Republic of Congo, a study by Sumaili et al. found that age above 65 years and hypertension were independently associated with increased risk of CKD stage 3-5 [24].

The issue of whether or not one should correct for the black African race when using eGFR equations has not been settled. Deventer et al. concluded that correction for the African race was not necessary when using the $4 \mathrm{v}-$ MDRD equation after they compared eGFR with mGFR in 100 black African patients with CKD and found a greater bias after correcting for race [5]. The mean weight of the participants in this study was $69.5 \mathrm{~kg}$ with a BSA of $1.76 \mathrm{~m}^{2}$ compared to a weight of $79.6 \mathrm{~kg}$ and BSA of $1.91 \mathrm{~m}^{2}$ for the MDRD population which included only 197 (12.1\%) African Americans [25]. The adjustment for the African race is extrapolated from the AfricanAmerican MDRD study population who had a higher mean weight and BSA compared to the Caucasian population necessitating a correction of the original $4 \mathrm{v}-\mathrm{MDRD}$ eGFR equation by a factor of 1.18 that was further adjusted to 1.212 after standardization of the creatinine assay. Since serum creatinine levels are affected by muscle mass, it is not surprising that the $4 \mathrm{v}-\mathrm{MDRD}$ equation without correction for race better approximated mGFR in the South African population given a closer similarity in weight and by extension muscle mass of their study population to the Caucasian population used in deriving the equation. A study carried out in Ghana in a rural population of black Africans also concluded that correction for race was unnecessary for both the $4 \mathrm{v}-\mathrm{MDRD}$ and CKDEPI equations. This study compared eGFR to $\mathrm{CrCl}$ and the mean weight of the participants was $54.4 \mathrm{~kg}$ [6]. Flamant et al. compared CKD-EPI and 4v-MDRD derived eGFR to mGFR in African Europeans originating from West Africa and concluded that a correction factor of 1.08 was required. However, most of the patients in this study had CKD with a mean mGFR of $57.6 \mathrm{ml} / \mathrm{min} / 1.73 \mathrm{~m}^{2}$ [26]. Delanaye et al. has argued that the correction factor for race when using the $4 \mathrm{v}-\mathrm{MDRD}$ or CKD-EPI equations should vary depending on whether it is being applied in individuals with CKD and an eGFR $<60 \mathrm{ml} / \mathrm{min} / 1.73 \mathrm{~m}^{2}$ or healthy subjects due to the inherent difference in how these 2 populations handle serum creatinine even within the same race [27]. In our study we didn't compare eGFR to either mGFR or $\mathrm{CrCl}$ but rather compared the proportion of healthy black Africans classified as having a reduced or normal eGFR across the different equations and eGFR correlation with a prediction model comprising risk factors for CKD. Since the correction factor for race for both $4 \mathrm{v}-\mathrm{MDRD}$ and CKD-EPI is greater than one, it is not surprising that correction for race resulted in higher eGFRs. However, the CKD EPI equation had a higher median eGFR and proportion of individuals with eGFR > $90 \mathrm{ml} / \mathrm{min} / 1.73 \mathrm{~m}^{2}$ compared to $4 \mathrm{v}-\mathrm{MDRD}$ or FAS as well as better correlation with risk factors for CKD. This is not surprising as CKD-EPI is more accurate than the $4 \mathrm{v}-$ MDRD equation in individuals with a GFR $>60 \mathrm{ml} / \mathrm{min} /$ $1.73 \mathrm{~m}^{2}$ and would be expected to be more appropriate for the subjectively healthy population recruited in this study [9]. The presence of a larger proportion of healthy individuals in the CKD-EPI dataset makes it more suitable for reporting eGFR in healthy subjects [21]. The FAS equation was developed to overcome the potential differences in eGFR associated with adoption of different equations. The equation incorporates population normalized serum creatinine levels and therefore gets rid of the need for further age, gender and race correction. This equation has been shown to be less biased than the CKD-EPI equation when applied on data sets largely comprised of a Caucasian population and therefore requires validation in an ethnic black African population [11]. In our study, the FAS determined eGFR had similar correlation coefficients with CKD risk factors as the $4 \mathrm{v}-\mathrm{MDRD}$ equation and demonstrated a similar pattern in change of mean eGFR with age where the mean eGFR in the age group 40-49 years was higher than in the age group 30-39 years. Of the 6 equations, only the CKD-EPI derived mean eGFRs showed a consistent decline with increase in age across the 4 age stratifications in line with the expected reduction of eGFR associated with progressive loss of nephrons above the age of 30 years [28].

The median eGFR for female participants calculated using the various equations was consistently higher than male participants in our study though this difference was not statistically significant except for eGFR determined using CG corrected for BSA. This is in contrast to the Ghanaian study by Eastwood et al. where the female participants had a lower mean eGFR when determined using both the $4 \mathrm{v}-\mathrm{MDRD}$ and CKD-EPI equations with and without correcting for race but not when CG corrected for BSA was used. Similar to our study, the Ghanaian women had a higher BMI but lower weight and blood pressure compared to the men [6]. No obvious explanation is forthcoming for the relatively better eGFR seen in women compared to men in our study. The Ghanaian rural population had a higher percentage $(13.2 \%)$ of individuals with reduced eGFR $\left(<60 \mathrm{ml} / \mathrm{min} / 1.73 \mathrm{~m}^{2}\right)$ 
compared to $<1 \%$ in our study population which can partially be explained by the fact that we recruited a younger population ranging from 18 to 65 years compared to $40-75$ years for the Ghanaian population with $50.8 \%$ of our study population being under the age of 40 years. We also had a strict inclusion and exclusion criteria to ensure that as far as possible only healthy individuals were recruited.

A major limitation of our study is that we didn't measure GFR and as such our comparison of various eGFR equations is not validated against a gold standard. In the absence of mGFR, we chose to use correlation with a prediction model of markers known to increase risk of CKD but are not included in the eGFR equations as a basis of comparison. Our assumption was that equations whose eGFR calculations best correlated with these risk factors were potentially better equations to be used when screening for CKD in an asymptomatic black African population. This is not equivalent to mGFR and therefore limits the extent to which conclusions can be made as to which equation is better. Another major limitation is that we didn't carry out any test for albuminuria neither did we repeat serum creatinine measurements after 3 months hence we cannot accurately comment on the prevalence of CKD in this population. Gharbi et al. found that 32\% of the subjects classified as having CKD stage $3 \mathrm{a}$ and $7.4 \%$ of those classified as $3 \mathrm{~b}$ had an eGFR $>60 \mathrm{ml} / \mathrm{min} / 1.73 \mathrm{~m}^{2}$ when reinvestigated after 3 months or longer [22]. However, the proportion of participants with an eGFR $<60 \mathrm{ml} / \mathrm{min} / 1.73 \mathrm{~m}^{2}$ in our study was less than $1 \%$ hence the risk of over diagnosing CKD in this healthy population was extremely low. What is more likely is that we may have under diagnosed CKD due to failure to test for albuminuria. We also assumed that diabetes and hypertension are the commonest risk factors for CKD in our population which may not necessarily be the case as demonstrated by Stanifer et al. in Northern Tanzania where $49.1 \%$ of individuals with CKD didn't have hypertension, diabetes or HIV [29]. We also didn't measure cystatin $C$ which has been shown by Meeusen et al. to significantly improve eGFR estimation across different patient groups including healthy kidney donors when incorporated into the CKD-EPI equation [30].

\section{Conclusion}

The CKD-EPI equation with correction for race classified the highest proportion of asymptomatic healthy black Africans as having an eGFR $>90 \mathrm{ml} / \mathrm{min} / 1.73 \mathrm{~m}^{2}$ and its eGFR better correlated with risk factors for CKD. For this reason, we recommend the use of the CKD-EPI equation with correction for race for routine reporting of eGFR in an asymptomatic black African population with a low prevalence of risk factors for CKD. Comparing eGFR to mGFR would be the best way to determine the most appropriate equation for CKD screening in an asymptomatic black African population. However, measurement of GFR is a complex and expensive process which serves as a barrier for the validation of eGFR equations especially in sub Saharan Africa. In the absence of mGFR, other ways of evaluating the potential utility and performance of eGFR equations in routine screening for CKD in asymptomatic populations need to be evaluated.

\section{Abbreviations}

4V-MDRD: Re-expressed 4 variable modified diet in renal disease:

Abd.Circ: Abdominal circumference; BMl: Body mass index; BP: Blood pressure; BSA: Body surface area; CG: Cockcroft-Gault; CKD: Chronic kidney disease; CKD-EPI: Chronic kidney disease epidemiology collaboration; $\mathrm{CrCl}$ : Creatinine clearance; eGFR: Estimated glomerular filtration rate; FAS: Full age spectrum; FPG: Fasting plasma glucose; GFR: Glomerular filtration rate; IQR: Interquartile range; KDIGO: Kidney Disease: Improving Global Outcomes; Max:: Maximum; MDRD: Modified diet in renal disease; mGFR: Measured glomerular filtration rate; Min.: Minimum; SD: Standard deviation

\section{Acknowledgements}

Jared Oseko and Patricia Ingato, Aga Khan University Hospital Nairobi, assisted in sample collection, bar coding and processing. Benjamin Matheka, marketing manager PathCare Kenya Ltd., assisted in participant recruitment and sample collection. Arno Theron carried out sample analysis, quality assurance and data handling at the Pathcare reference laboratory in Cape Town, South Africa. Dr. Mathew Koech, nephrology fellow at Stellenbosch University, for reviewing the manuscript.

\section{Funding}

Part of this study was funded by an Aga Khan University Research Council grant (URC Project ID: 1420088A). The funding body played no role in the design of the study, sample collection, analysis, interpretation of data and in writing the manuscript. Dr. Kiran Radia, the Chief Executive officer and Pathologist at PathCare Kenya Ltd. provided resources that facilitated study coordination, sample collection, processing, quality assurance and shipping to the PathCare reference laboratory in Cape town, South Africa.

Availability of data and materials

Not shared as it contains confidential participant data.

Author's contributions

GO designed the study, collected data, performed statistical analysis and wrote the manuscript. DM designed the study, collected data and critiqued the manuscript, JM and CW designed the study and critiqued the manuscript, AK and EK collected data and critiqued the manuscript, AA, PJ and RE designed the study, planned and supervised its implementation, critiqued the manuscript. All authors read and approved the final manuscript.

Ethics approval and consent to participate

Ethical approval was obtained from the Aga Khan University, Nairobi Health Research Ethics Committee (2014/REC-46). Written informed consent was obtained from all participants.

Consent for publication

Not applicable.

Competing interests

The authors declare that they have no competing interests.

\section{Publisher's Note}

Springer Nature remains neutral with regard to jurisdictional claims in published maps and institutional affiliations. 


\section{Author details}

Department of Pathology, Aga Khan University Hospital Nairobi, P.O. Box 30270-00100, Nairobi, Kenya. ${ }^{2}$ PathCare Kenya Ltd., P.O. Box 12560-00606, Nairobi, Kenya. ${ }^{3}$ Department of Pathology, Aga Khan Hospital, P.O. Box 2289, Dar es Salaam, Tanzania. ${ }^{4}$ Department of Human Pathology, University of Nairobi, P.O. Box 19676-00200, Nairobi, Kenya. ${ }^{5}$ Department of Pathology, Maseno University, P.O. Box Private Bag, Maseno, Kenya. ${ }^{6}$ Division of Chemical Pathology, Department of Pathology, Stellenbosch University, P.O. Box 19113, Tygerberg Hospital, Cape Town, South Africa.

Received: 26 May 2016 Accepted: 11 December 2017 Published online: 20 December 2017

\section{References}

1. Noble E, Johnson DW, Gray N, Hollett P, Hawley CM, Campbell SB, Mudge DW, Isbel NM. The impact of automated eGFR reporting and education on nephrology service referrals. Nephrol Dial Transplant. 2008;23:3845-50.

2. Levey AS, Atkins R, Coresh J, Cohen EP, Collins AJ, Eckardt K-U, Nahas ME, Jaber BL, Jadoul M, Levin A, Powe NR, Rossert J, Wheeler DC, Lameire N, Eknoyan G. Chronic kidney disease as a global public health problem: approaches and initiatives - a position statement from kidney disease improving global outcomes. Kidney Int. 2007;72:247-59.

3. Cockcroft DW, Gault MH. Prediction of creatinine clearance from serum creatinine. Nephron. 1976:16:31-41.

4. Levey AS, Bosch JP, Lewis JB, Greene T, Rogers N, Roth D. A more accurate method to estimate glomerular filtration rate from serum creatinine: a new prediction equation. Modification of diet in renal disease study group. Ann Intern Med. 1999;130:461-70.

5. van Deventer HE, George JA, Paiker JE, Becker PJ, Katz IJ. Estimating glomerular filtration rate in black south Africans by use of the modification of diet in renal disease and Cockcroft-Gault equations. Clin Chem. 2008;54: 1197-202

6. Eastwood JB, Kerry SM, Plange-Rhule J, Micah FB, Antwi S, Boa FG, Banerjee D, Emmett L, Miller MA, Cappuccio FP. Assessment of GFR by four methods in adults in Ashanti, Ghana: the need for an eGFR equation for lean African populations. Nephrol Dial Transplant. 2010;25:2178-87.

7. Vervoort G, Willems HL, Wetzels JFM. Assessment of glomerular filtration rate in healthy subjects and normoalbuminuric diabetic patients: validity of a new (MDRD) prediction equation. Nephrol Dial Transplant. 2002;17:1909-13.

8. Ibrahim H, Mondress M, Tello A, Fan Y, Koopmeiners J, Thomas W. An alternative formula to the Cockcroft-Gault and the modification of diet in renal diseases formulas in predicting GFR in individuals with type 1 diabetes. J Am Soc Nephrol. 2005;16:1051-60.

9. Levey AS, Stevens LA, Schmid CH, Zhang YL, Castro AF, Feldman HI, Kusek JW, Eggers $P$, Van Lente F, Greene T, Coresh J. A new equation to estimate glomerular filtration rate. Ann Intern Med. 2009;150:604-12.

10. Wyatt CM, Schwartz GJ, Owino Ong'or W, Abuya J, Abraham AG, Mboku C, M'mene LB, Koima WJ, Hotta M, Maier P, Klotman PE, Wools-Kaloustian K. Estimating kidney function in HIV-infected adults in Kenya: comparison to a direct measure of glomerular filtration rate by iohexol clearance. PLoS One. 2013;8:e69601

11. Pottel H, Hoste L, Dubourg L, Ebert N, Schaeffner E, Eriksen BO, Melsom T, Lamb EJ, Rule AD, Turner ST, Glassock RJ, De Souza V, Selistre L, Mariat C, Martens F, Delanaye P. An estimated glomerular filtration rate equation for the full age spectrum. Nephrol Dial Transplant. 2016;31:798-806.

12. Stevens LA, Coresh J, Greene T, Levey AS. Assessing kidney function-measured and estimated glomerular filtration rate. N Engl J Med. 2006;354:2473-83.

13. Ozarda Y, Ichihara K, Barth JH, Klee G. Protocol and standard operating procedures for common use in a worldwide multicenter study on reference values. Clin Chem Lab Med. 2013:51:1027-40.

14. Omuse G, Maina D, Hoffman M, Mwangi J, Wambua C, Kagotho E, Amayo A, Ojwang P, Premji Z, Ichihara K, Erasmus R. Metabolic syndrome and its predictors in an urban population in Kenya: a cross sectional study. BMC Endocr Disord. 2017;17:37.

15. DuBois DDE. A formula to estimate the approximate surface area if height and weight be known. Arch Intern Med. 1916;17:863-71.

16. Levey AS, Coresh J, Greene T, Marsh J, Stevens LA, Kusek JW, Van Lente F. Expressing the modification of diet in renal disease study equation for estimating glomerular filtration rate with standardized serum creatinine values. Clin Chem. 2007;53:766-72.
17. KDIGO. KDIGO 2012 clinical practice guideline for the evaluation and Management of Chronic Kidney Disease. Kidney Int Suppl. 2013:3:4-4

18. Pottel $H$, Hoste $L$, Delanaye P. Abnormal glomerular filtration rate in children, adolescents and young adults starts below $75 \mathrm{~mL} / \mathrm{min} / 1.73 \mathrm{~m}^{2}$ Pediatr Nephrol. 2015;30:821-8.

19. CLSI. Defining, establishing, and verifying reference intervals in the clinical laboratory; approved guideline. Third ed. Wayne PA: Clinical and Laboratory Standards Institute; 2008.

20. Kaze FF, Meto DT, Halle M-P, Ngogang J, Kengne A-P, Lozano R, Naghavi M, Foreman K, Lim S, Shibuya K, Aboyans V, Abraham J, Adair T, Aggarwal R, Ahn S, Naicker S, Marshall S, Bamgboye E, Eastwood J, Kerry S, Plange-Rhule J, Micah F, Antwi S, Boa F, Banerjee D, Emmett L, Miller M, Cappuccio F, Sumaili E, Nseka N, et al. Prevalence and determinants of chronic kidney disease in rural and urban Cameroonians: a cross-sectional study. BMC Nephrol. 2015:16:117.

21. Rule AD, Rodeheffer RJ, Larson TS, Burnett JC, Cosio FG, Turner ST, Jacobsen SJ. Limitations of estimating glomerular filtration rate from serum creatinine in the general population. Mayo Clin Proc. 2006;81:1427-34.

22. Benghanem Gharbi M, Elseviers M, Zamd M, Belghiti Alaoui A, Benahadi N, Trabelssi EH, Bayahia R, Ramdani B, De Broe ME, Eckardt KU, Coresh J, Devuyst O, Group KDIGO (KDIGO) CW, Luyckx VA, Naicker S, McKee M, Naicker S, McCullough K, Sharma P, Ali T, Brück K, Jager KJ, Dounousi E, Zhang QL, Rothenbacher D, Anothaisintawee T, Rattanasiri S, et al. Chronic kidney disease, hypertension, diabetes, and obesity in the adult population of Morocco: how to avoid "over"- and "under"-diagnosis of CKD. Kidney Int. 2016:89:1363-71.

23. Matsha TE, Yako YY, Rensburg MA, Hassan MS, Kengne AP, Erasmus RT. Chronic kidney diseases in mixed ancestry south African populations: prevalence, determinants and concordance between kidney function estimators. BMC Nephrol. 2013;14:75.

24. Sumaili EKK, Krzesinski J-MM, Zinga CW, Cohen EPP, Delanaye P, Munyanga SMM, Nseka NMM. Prevalence of chronic kidney disease in Kinshasa: results of a pilot study from the Democratic Republic of Congo. Nephrol Dial Transpl. 2009;24:117-22.

25. Levey AS, Bosch JP, Lewis JB, Greene T. A more accurate method to estimate glomerular filtration rate from serum creatinine: a new prediction equation. Modification of Diet in Renal Disease Study Group. 1999;130:461-70.

26. Flamant M, Vidal-Petiot E, Metzger M, Haymann J-P, Letavernier E, Delatour V, Karras A, Thervet E, Boffa J-J, Houillier P, Stengel B, Vrtovsnik F, Froissart M, Maple-Brown LJ, Hughes JT, Lawton PD, Teo BW, Xu H, Wang D, Stevens LA, Claybon MA, Schmid CH, Moranne O, Froissart M, Rossert J, Froissart M, et al. Performance of GFR estimating equations in African Europeans: basis for a lower race-ethnicity factor than in African Americans. Am J Kidney Dis. 2013;62:182-4.

27. Delanaye P, Mariat C, Maillard N, Krzesinski J-M, Cavalier E. Are the creatinine-based equations accurate to estimate glomerular filtration rate in African American populations? Clin J Am Soc Nephrol. 2011;6:906-12.

28. Glassock RJ, Rule AD. Aging and the kidneys: anatomy, physiology and consequences for defining chronic kidney disease. Nephron. 2016;134:25-9.

29. Stanifer JW, Maro V, Egger J, Karia F, Thielman N, Turner EL, Shimbi D, Kilaweh H, Matemu O, Patel UD. The epidemiology of chronic kidney disease in northern Tanzania: a population-based survey. PLoS One. 2015;10: e0124506.

30. Meeusen JW, Rule AD, Voskoboev N, Baumann NA, Lieske JC. Performance of cystatin C- and creatinine-based estimated glomerular filtration rate equations depends on patient characteristics. Clin Chem. 2015;61:1265-72. 